\title{
BMJ Open US-county level variation in intersecting individual, household and community characteristics relevant to COVID-19 and planning an equitable response: a cross-sectional analysis
}

\author{
Taylor Chin (1) , ${ }^{1}$ Rebecca Kahn (1) , ${ }^{1}$ Ruoran Li (D) , Jarvis T Chen (i) , \\ Nancy Krieger (D) , ${ }^{2}$ Caroline O Buckee, ${ }^{1}$ Satchit Balsari, ${ }^{3,4}$ Mathew V Kiang (D) ${ }^{4,5,6}$
}

To cite: Chin T, Kahn R, Li R, et al. US-county level variation in intersecting individual, household and community characteristics relevant to COVID-19 and planning an equitable response: a crosssectional analysis. BMJ Open 2020;10:e039886. doi:10.1136/ bmjopen-2020-039886

- Prepublication history and additional material for this paper are available online. To view these files, please visit the journal online (http://dx.doi. org/10.1136/bmjopen-2020039886).

TC and RK are joint first authors. SB and MVK are joint senior authors.

Received 29 April 2020

Revised 13 July 2020

Accepted 17 August 2020

A Check for updates

(C) Author(s) (or their employer(s)) 2020. Re-use permitted under CC BY-NC. No commercial re-use. See rights and permissions. Published by BMJ.

For numbered affiliations see end of article.

Correspondence to

Taylor Chin;

taylorchin@g.harvard.edu

\section{ABSTRACT}

Objectives To illustrate the intersections of, and intercounty variation in, individual, household and community factors that influence the impact of COVID-19 on US counties and their ability to respond.

Design We identified key individual, household and community characteristics influencing COVID-19 risks of infection and survival, guided by international experiences and consideration of epidemiological parameters of importance. Using publicly available data, we developed an open-access online tool that allows county-specific querying and mapping of risk factors. As an illustrative example, we assess the pairwise intersections of age (individual level), poverty (household level) and prevalence of group homes (community-level) in US counties. We also examine how these factors intersect with the proportion of the population that is people of colour (ie, not non-Hispanic white), a metric that reflects histories of US race relations. We defined 'high' risk counties as those above the 75th percentile. This threshold can be changed using the online tool.

Setting US counties.

Participants Analyses are based on publicly available county-level data from the Area Health Resources Files, American Community Survey, Centers for Disease Control and Prevention Atlas file, National Center for Health Statistic and RWJF Community Health Rankings.

Results Our findings demonstrate significant intercounty variation in the distribution of individual, household and community characteristics that affect risks of infection, severe disease or mortality from COVID-19. About 9\% of counties, affecting 10 million residents, are in higher risk categories for both age and group quarters. About $14 \%$ of counties, affecting 31 million residents, have both high levels of poverty and a high proportion of people of colour.

Conclusion Federal and state governments will benefit from recognising high intrastate, intercounty variation in population risks and response capacity. Equitable responses to the pandemic require strategies to protect those in counties at highest risk of adverse COVID-19 outcomes and their social and economic impacts.

\section{Strengths and limitations of this study}

- By demonstrating the high intercounty variation in a range of risk factors across US counties, including their intersection with communities of colour, this study highlights the need for policy-makers to consider their local context when addressing the COVID-19 pandemic.

- Approximately $9 \%$ of counties, affecting 10 million residents, are in higher risk categories for both age and group quarters, while approximately $14 \%$ of counties, affecting 31 million residents, have both high levels of poverty and a high proportion of people of colour.

- This study provides scientific guidance and an interactive data exploration tool to assist county-level and state-level policy-makers in planning an equitable response to COVID-19.

- While the list of variables examined is not exhaustive, an interactive online tool is made available for users to examine and compare 24 county-level characteristics.

- The study does not attempt to assign weights to these various risk factors, as it is not yet clear to how they will differentially impact risk of infection from COVID-19, and subsequent morbidity and mortality from it.

\section{INTRODUCTION}

The spread of COVID-19 across the USA confirms that not all Americans are equally at risk of infection, severe disease, or mortality. Researchers have noted significant disparities in the availability of critical medical resources that impact COVID-19 survival, such as ventilators, hospital beds and intensive care unit (ICU) beds. ${ }^{1-4}$ However, a range of individual, household and community characteristics also influence risk of COVID-19 infection and its lethality. Preliminary data from the epidemic demonstrate a convergence of 
these risk factors in communities with high proportions of low-income households, people of colour or both, differentially affecting counties across the USA. ${ }^{5-7}$

In this paper, we demonstrate wide intercounty variation in individual, household and community factors that influence risk of COVID-19 outcomes and provide an online tool for policy-makers to examine county-specific risk factors to plan an appropriate response (https:// ccdd-hsph-harvard.shinyapps.io/county-risk/).

Current literature indicates that individual-level factors like age and pre-existing health conditions influence COVID-19 susceptibility and survival. ${ }^{589}$ March 2020 data from a hospital-based surveillance system (COVID-NET) confirmed that $75 \%$ of all hospitalisations across 14 states in the USA were among those aged $\geq 50$ years, with the highest hospitalisation rates among those aged $\geq 65$. $^{5}$ Approximately $89 \%$ of COVID-19-associated hospitalised patients had one or more underlying conditions, including hypertension, obesity, chronic lung disease, diabetes and cardiovascular disease. ${ }^{5}$

Household characteristics such as household size, household composition (eg, grandparents living with grandchildren) and household crowding may affect contact patterns and transmission rates. ${ }^{10}$ Moreover, poverty and job insecurity determine people's ability to work from home and 'shelter in place', at a time when non-pharmaceutical interventions are currently the primary defence against the outbreak. ${ }^{11}{ }^{12}$ Poverty heightens susceptibility to COVID-19 infection and risk of severe outcomes, due to its association with higher risk of comorbidities, ${ }^{13}$ decreased access to care ${ }^{1314}$ and reduced ability to practice social distancing. ${ }^{1516}$ By April 2020, the Bronx, Philadelphia and Orleans Parishcounties with approximately one-fourth or more of its population below the poverty line-were among the counties with the highest cumulative death counts in the USA. ${ }^{17}$ Community characteristics involving the presence of group quarters ${ }^{18}$ such as correctional facilities, ${ }^{19} 20$ nursing homes ${ }^{21-23}$ and homeless shelters, ${ }^{24} 25$ are also implicated in COVID-19 risks. Local hospital-bed and ICU-bed capacity further determines a community's ability to respond to COVID-19. ${ }^{3}$

The intersection of these individual, household and community characteristics among communities of colour, created and perpetuated by the pervasive structural inequities in the USA, results in poor health outcomes. ${ }^{26-28}$ Communities of colour are more likely to include lowincome essential workers who cannot stay home, thereby increasing risk of exposure at work or on public transportation while commuting, as well as to live in more crowded housing. ${ }^{29}$ In addition to increased risk of infection and mortality, communities of colour have increased risk of chronic diseases ${ }^{30}$ and experience unequal access to healthcare,${ }^{631} 32$ further compounding risk of COVID-19 mortality. Populations of colour are also disproportionately unemployed $^{33}$ and incarcerated, ${ }^{34}$ which independently increase the risk of COVID-19 infection and severe outcomes. These disparities, as manifestations of the effects of systemic racism in the USA, contribute to higher COVID-19 death rates among predominantly black counties relative to predominantly white counties, ${ }^{35}$ as well as to their higher agespecific risks of mortality among working-age adults. ${ }^{36}$ Data from Detroit, New York City, New Orleans and Chicagoall cities with significant minority populations-reveal that African Americans comprise a disproportionate proportion of COVID-19 cases and deaths, relative to their share of the population..$^{31} 3537$

Understanding the distribution of these intersecting county-specific risk factors is critical to mounting an equitable, adequate, timely and comprehensive response. Inter-county differences are particularly important to consider in the context of supportive local policies around social distancing as the epidemic unfolds, and for the relaxation of social distancing in the coming months. Counties often have flexibility in determining the stringency of their COVID-19 response relative to their respective state orders ${ }^{3839}$; therefore, counties represent a spatial and administrative unit ideal for localised response. Local response measures include both mobilisation of healthcare resources and optimisation of policies for social distancing and reopening. We provide an illustrative example of the convergence of individual, household and community factors, including their racial/ethnic composition, across all US counties to identify counties at heightened COVID-19 risk.

\section{METHODS}

Using publicly available county-specific data from the Area Health Resources Files, ${ }^{40}$ American Community Survey, ${ }^{41}$ Centers for Disease Control and Prevention Atlas file, ${ }^{42}$ National Center for Health Statistics ${ }^{43}$ and RWJF Community Health Rankings, ${ }^{44}$ we identified a range of key individual, household and community factors influencing susceptibility to COVID-19, guided by international experiences and consideration of epidemiological parameters of importance. As an illustrative example, we examine the different pairwise intersections of age (an individual characteristic), poverty (a household characteristic) and prevalence of group homes (a community characteristic) in counties across the USA. We also examine how these factors intersect with the proportion of the population that is people of colour (ie, population other than non-Hispanic white), a metric that reflects histories of US race relations.

The accompanying open-access online tool (online supplementary materials text $\mathrm{S} 1$ ) is populated with each of these covariates and allows county-specific querying of different pairs of risk factors. In addition to displaying the county's rank relative to other counties, we display bivariate maps that illustrate the intersection of risk factors across the USA. All our data and code are publicly available to facilitate more nuanced analysis, inform existing models and shape policy (online supplementary materials text S1). For all covariates, we define low, medium and high risk as the below the 25th percentile, the 25-75th 
percentiles and above the 75th percentile, respectively. These thresholds can be changed using the online tool.

Patient and public involvement

Patients and the public were not involved in any way.

\section{RESULTS}

\section{Age and poverty}

With respect to age, each county in the top quartile had at least $15 \%$ of their population over 70 years of age, compared with the median county of $12.8 \%$. These older counties are clustered in the Midwest, Idaho, Florida and Nevada (online supplementary figure S1). For poverty, each county in the top quartile had at least $19 \%$ of their households under the poverty line, compared with the median county of $14.8 \%$. These high poverty counties are clustered around Appalachia, Deep South states and along the USA-Mexico border (online supplementary figure S2). About $4 \%$ of US counties (135 of 3106), affecting over 2 million people, have both an older population and high rates of poverty (figure 1A). These counties are geographically dispersed, with little signs of clustering. The most impacted states are Florida (295718 people in 7 of 67 counties), Arizona (198858 people in 3 of 15 counties) and Arkansas (159733 people in 14 of 75 counties).

\section{Poverty and group quarters}

For group quarters, each county in the top quartile had at least $4 \%$ of the resident population living in group quarters, compared with the median county of $1.9 \%$. These counties are geographically dispersed across the entire USA (online supplementary figure S3). Nearly $4 \%$ of US counties (112 of 3111 ), affecting 2.2 million people, have both high poverty rates and are in the top quartile of proportion of the population living in group quarters (figure 1B). While these counties are clustered in Louisiana, Florida and New Mexico, the states with the most people affected are Pennsylvania (290418 people in 6 of 67 counties), Florida (218325 people in 6 of 67 counties) and New York (191031 people in 4 of 62 counties).

\section{Age and group quarters}

Over 9\% of US counties (285 of 3106), affecting over 10 million people, have both an older population and are in the top quartile of proportion of the population living in group quarters (figure 1C). These counties are geographically dispersed and show few signs of clustering. The most impacted states are Texas (1.4million people in 40 of 254 counties), Georgia (1.2 million people in 20 of 67 counties) and Florida (711 168 people in 20 of 67 counties).

\section{Intersections of individual, household and community characteristics in communities with a high proportion of people of colour}

Regarding the composition of county populations, one quarter of counties in the USA (761) have at least $35 \%$ of their resident populations that are populations of colour (online supplementary figure S4). In 3\% of US counties
(89 of 3111), affecting 3.5 million people, the counties include both a high proportion of people of colour and a high proportion of older residents (figure 2A). In 14\% of US counties (424 of 3106), affecting 31 million people, the counties include both a high proportion of people of colour and a high proportion of households living under the poverty line (figure $2 \mathrm{~B}$ ). In about $7 \%$ of US counties (229 of 3111), affecting 14 million people, the counties have both a high proportion of people of colour and are in the top quartile of proportion of people living in group quarters (figure $2 \mathrm{C}$ ). Across the three risk factors, the intersection with counties with a high proportion of people of colour exhibits geographical variation. For example, clusters of counties with large populations of colour and older populations are found in Arizona, New Mexico and Colorado, but pockets also exist in Texas and Florida. This pattern is similar for counties with a high proportion of people of colour and proportion of people living in group quarters. By contrast, clusters of counties with a high proportion of people of colour and high poverty rates exist in the Deep South, in addition to Arizona, New Mexico and Texas.

\section{DISCUSSION}

\section{Principal findings}

Many Americans with chronic comorbidities, lack (and recent loss) of health insurance, inability to work from home and limited access to care are likely to be disproportionately affected by COVID-19, due to their increased risk of both infection and severe disease. Our findings demonstrate significant intercounty variation in the distribution of these risks, including their intersection with communities of colour.

\section{Meaning of the study}

Many of the counties that carry intersecting risks are located in states that have been tepid in their socialdistancing response or in a haste to re-open. ${ }^{6}{ }^{45-47}$ In the absence of measures to enable social distancing and provision of adequate personal protective equipment to those that cannot stay home, communities of colour will likely continue to bear a disproportionately high burden of infection, severe disease and mortality. ${ }^{6} 313537$

Areas with greater COVID-19 risk will likely have greater demand for hospital beds, and the ability of counties to mount a medical response to the outbreak will depend on local bed capacity. However, there is substantial geographical variation in hospital bed capacity. The median county has approximately 185 hospital beds per 100000 population (mean: 294; IQR: 69-357; online supplementary figure S5). According to a May 2020 report from the US Society for Critical Care Medicine, only 1\% (963) of all ICU beds are located in rural areas. ${ }^{48}$ (See online supplementary figures S6-S9 for intersection of factors examined above and bed capacity.) In anticipation of heightened demands on healthcare systems during future waves of COVID-19 in counties that are multiply 
A
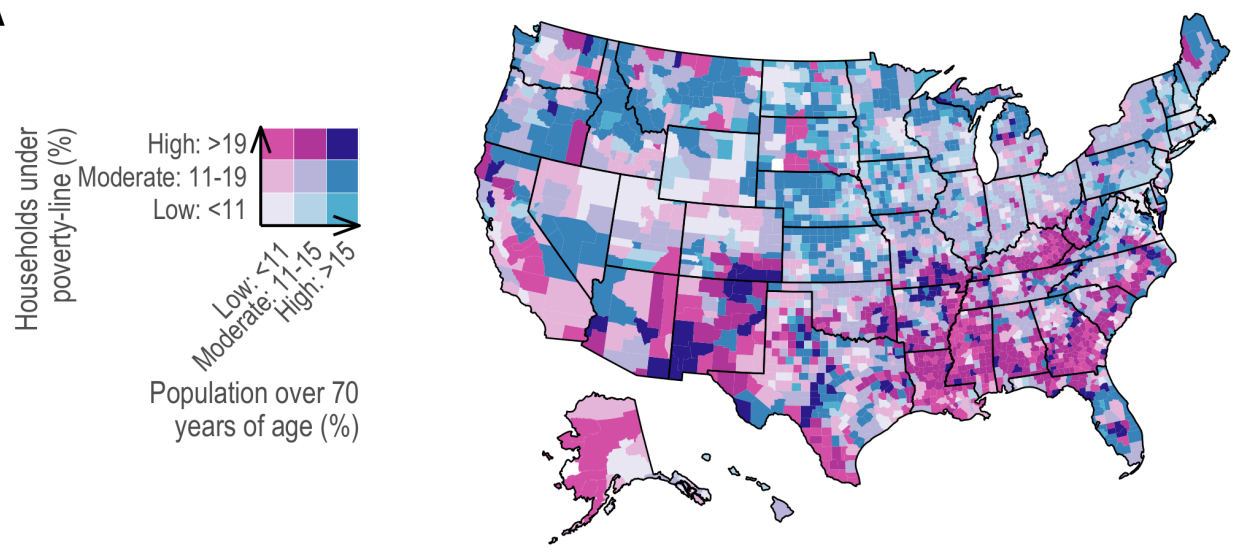

$\mathbf{B}$
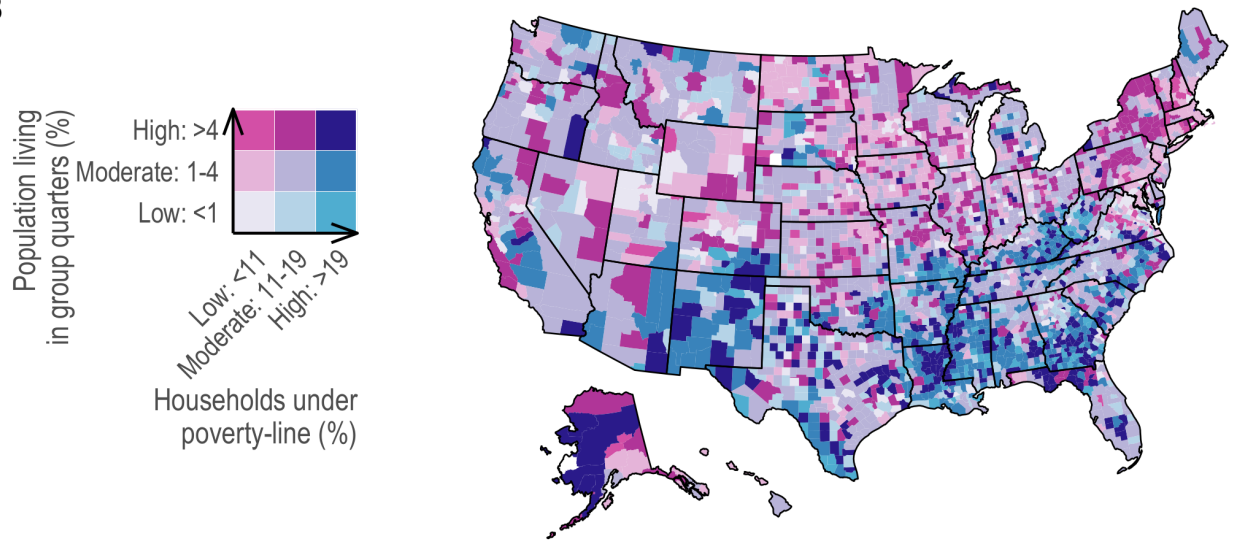

C
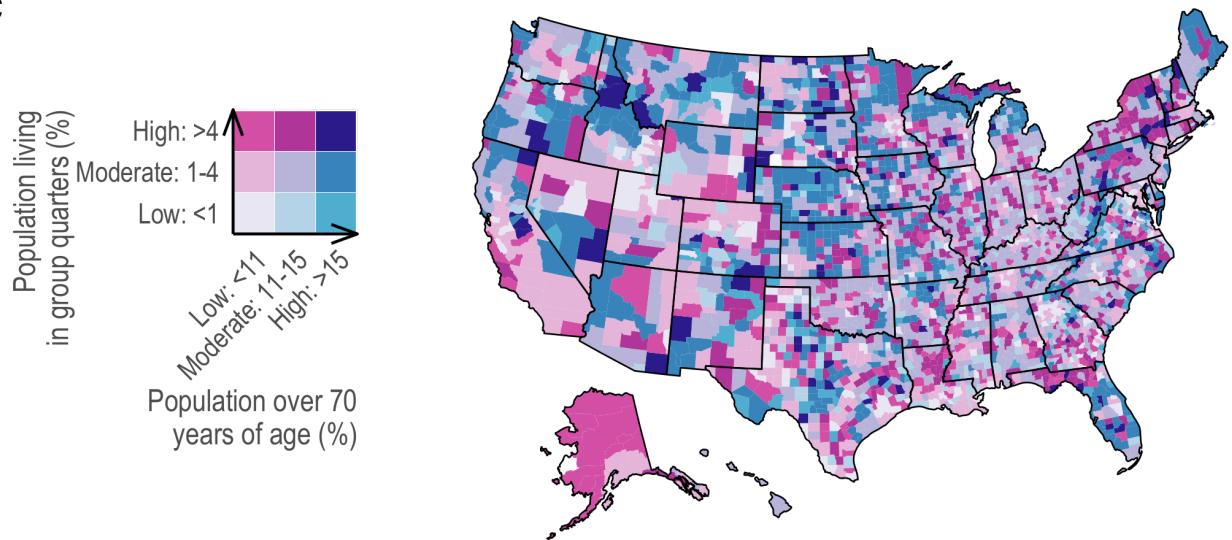

Figure 1 (A) Percentage of households living in poverty, 2016 (Source: CDC Atlas via the Census Small Area Income and Policy Estimates) and percentage of population 70years or older, 2018 (Source: National Center for Health Statistics Bridged Race Population Estimates 2018, Vintage 2018). (B) Percentage of population living in group quarters, 2018 (Source: American Community Survey) and percentage of households living in poverty, 2016 (Source: CDC Atlas via the Census Small Area Income and Policy Estimates). (C) Percentage of population living in group quarters, 2018 (Source: American Community Survey) and percentage of population 70 years or older, 2018 (Source: National Center for Health Statistics Bridged Race Population Estimates 2018, Vintage 2018).

at risk of having high COVID-19 burden, states and the federal government need to ramp up interjurisdictional coordination efforts to move supplies and personnel to meet rapidly shifting local demands.

\section{Limitations and future research}

The risk factors described here are by no means a comprehensive list. Other important county-level characteristics are shown in online supplementary figures S10-S22 and can be found in the online dashboard. Additional risk factors on the county level that are not included in this analysis, such as the proportion of workers in industries that preclude working remotely, language, immigration status, numbers of incarcerated and homeless persons, measures of inequality like the Gini coefficient and Index of Concentration at the Extremes, and density of residential drug treatment programmes and residential mental health 
A
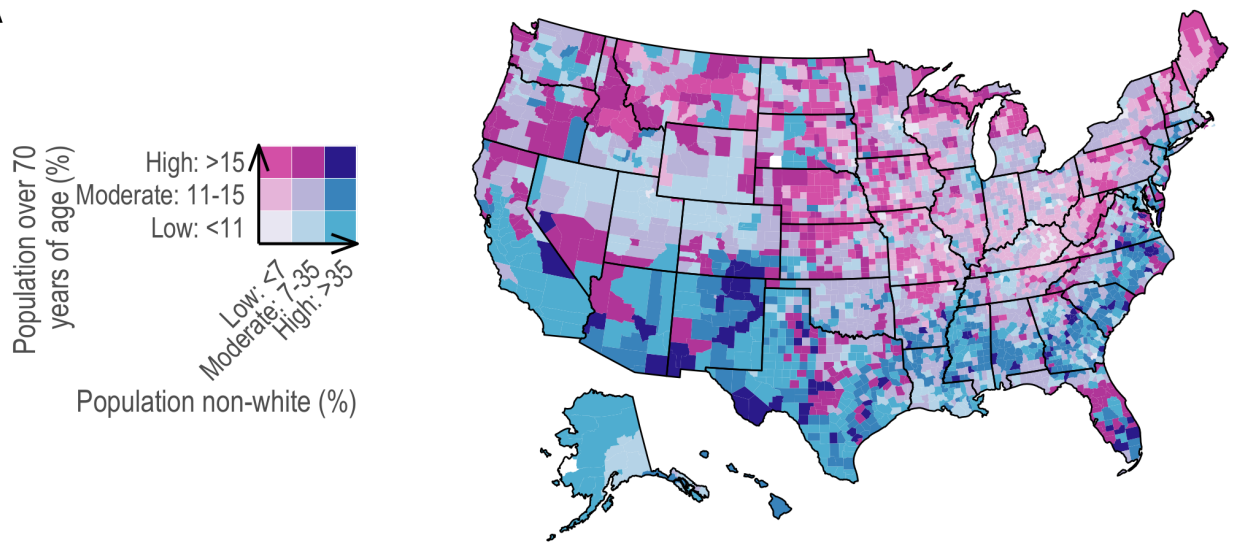

B
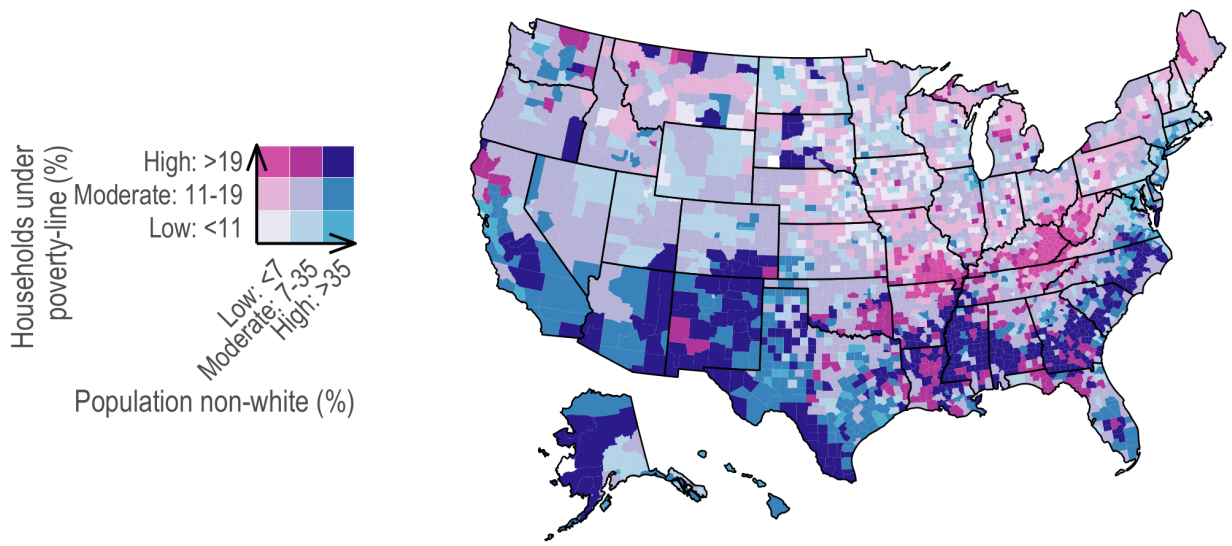

C
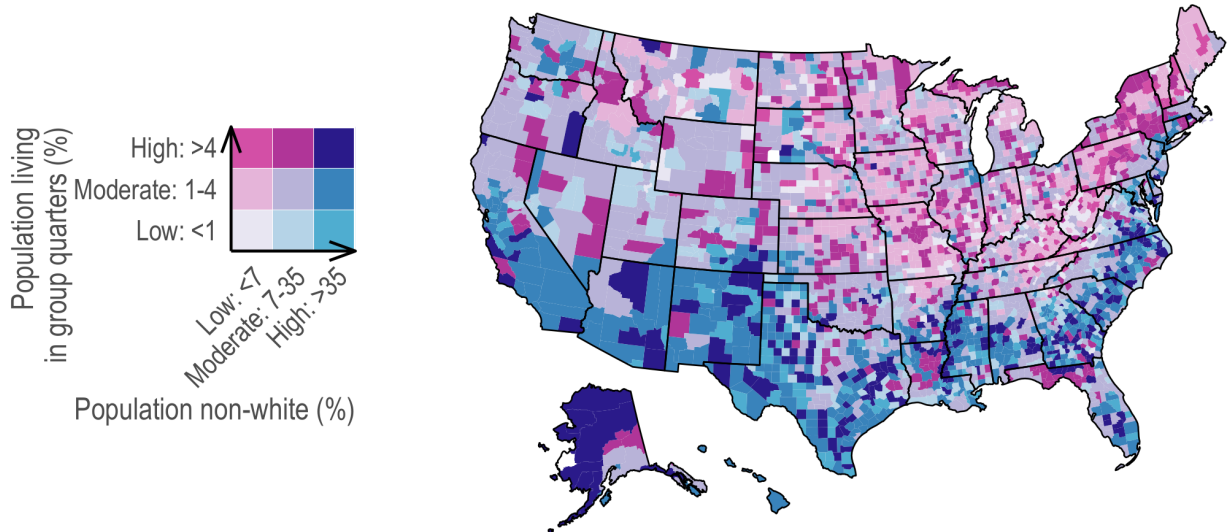

Figure 2 (A) Percentage of population 70 years or older, 2018 (Source: National Center for Health Statistics Bridged Race Population Estimates 2018, Vintage 2018) and percentage of population non-Hispanic and non-white, 2018 (Source: National Center for Health Statistics). (B) Percentage of households living in poverty, 2016 (Source: CDC Atlas via the Census Small Area Income and Policy Estimates) and percentage of population non-Hispanic and non-white, 2018 (Source: National Center for Health Statistics). (C) Percentage of population living in group quarters, 2018 (Source: American Community Survey) and percentage of population non-Hispanic and non-white, 2018 (Source: National Center for Health Statistics).

facilities, may all contribute to how counties are affected and respond. Currently, there is insufficient evidence to justify assigning importance weights to different risk factors; however, as more data become available, future research may expand on our analysis by, for example, constructing and evaluating a polysocial risk score. ${ }^{49}$

\section{Conclusion}

By July 6, there were more than 2.9 million cases in the USA, across all states, Washington D.C., and four US territories. ${ }^{50}$ County, state and national planners will benefit from examining and preparing for the local factors that are likely to influence their counties' ability to respond. The need for actionable, contextually relevant data that allows for equitable distribution of resources to prevent, mitigate and treat COVID-19 is imperative. Collecting and sharing data on COVID-19 outcomes by race and ethnicity, which surveillance systems have not systematically reported for testing or hospitalisation (but 
which are increasingly including these data for mortality), will be crucial to understanding and rectifying inequities in the distribution of COVID-19 outcomes. ${ }^{1751}$

The clustering of counties with high concentrations of people of colour and high rates of poverty can be traced back to legacies of Jim Crow and race relations in the South. ${ }^{27} 28$ In the absence of concerted, aggressive and proactive local responses, supported by state and federal agencies, the final morbidity and mortality toll, as early numbers indicate, will be disproportionately borne by these communities. Inaction will only perpetuate the structural inequities that are deeply entrenched in the USA.

\section{Author affiliations}

${ }^{1}$ Epidemiology, Harvard University T H Chan School of Public Health, Boston, Massachusetts, USA

${ }^{2}$ Social and Behavioral Sciences, Harvard TH Chan School of Public Health, Boston, MA, United States

${ }^{3}$ Emergency Medicine, Beth Israel Deaconess Medical Center, Harvard Medical School, Boston, Massachusetts, USA

${ }^{4}$ FXB Center for Health and Human Rights, Harvard University, Cambridge,

Massachusetts, USA

${ }^{5}$ Center for Population Health Sciences, Stanford University, Palo Alto, California, USA

${ }^{6}$ Epidemiology and Population Health, Stanford University, Stanford, California, USA

Twitter Rebecca Kahn @rebeccajk13, Ruoran Li @ruoranepi and Mathew V Kiang @mathewkiang

Acknowledgements The authors thank Ayesha S. Mahmud, Nishant Kishore and Tori Cowger for their valuable input and feedback.

Contributors SB and MVK conceived and designed the project. TC, RK, RL and MVK acquired and analysed the data. NK contributed to framing the conceptualisation and discussion of the individual, household and community characteristics. All authors interpreted the results. TC and RK drafted the first version of the manuscript. All authors provided critical input for subsequent revisions. All authors approve of the final version to be published. All authors agree to be accountable for this work and ensure the accuracy and integrity of the work will be appropriately investigated and resolved.

Funding TC, RK and RL were supported in part by Award Number U54GM088558 from the US National Institute of General Medical Sciences. NK was supported in part by her American Cancer Society Clinical Research Professor Award. MVK was supported by the National Institute on Drug Abuse of the National Institutes of Health (K99DA051534).

Disclaimer Dissemination of the results to study participants and or patient organisation is not applicable. The content is solely the responsibility of the authors and does not necessarily represent the official views of the National Institute of General Medical Sciences, National Institute on Drug Abuse, the National Institutes of Health, or other contributing agencies. The authors conducted the study independently, and the decision to submit the manuscript for publication was theirs alone.

Map disclaimer The depiction of boundaries on this map does not imply the expression of any opinion whatsoever on the part of BMJ (or any member of its group) concerning the legal status of any country, territory, jurisdiction or area or of its authorities. This map is provided without any warranty of any kind, either express or implied.

Competing interests None declared.

Patient consent for publication Not required.

Provenance and peer review Not commissioned; externally peer reviewed.

Data availability statement Data are available in a public, open access repository. We provide data and code to reproduce this paper at https://github.com/mkiang/ county_preparedness/.

Open access This is an open access article distributed in accordance with the Creative Commons Attribution Non Commercial (CC BY-NC 4.0) license, which permits others to distribute, remix, adapt, build upon this work non-commercially, and license their derivative works on different terms, provided the original work is properly cited, appropriate credit is given, any changes made indicated, and the use is non-commercial. See: http://creativecommons.org/licenses/by-nc/4.0/.

\section{ORCID iDs}

Taylor Chin http://orcid.org/0000-0001-6852-1169

Rebecca Kahn http://orcid.org/0000-0001-9511-6142

Ruoran Li http://orcid.org/0000-0001-7575-2758

Jarvis T Chen http://orcid.org/0000-0002-7412-1783

Nancy Krieger http://orcid.org/0000-0002-4815-5947

Mathew V Kiang http://orcid.org/0000-0001-9198-150X

\section{REFERENCES}

1 Predicting the effects of the COVID pandemic on US health system capacity, 2020. Available: https://qventus.com/blog/predictingthe-effects-of-the-covid-pandemic-on-us-health-system-capacity/ [Accessed 18 Mar 2020].

2 Waldman A, Shaw A, Ngu A, et al. Are hospitals near me ready for coronavirus? here are nine different scenarios. Available: https:// projects.propublica.org/graphics/covid-hospitals [Accessed $18 \mathrm{Mar}$ 2020].

3 Miller IF, Becker AD, Grenfell BT, et al. Disease and healthcare burden of COVID-19 in the United States. Nat Med 2020;26:1212-7.

4 COVID-19 Projections. Institute for health metrics and evaluation, 2020. Available: https://covid19.healthdata.org/projections [Accessed 6 Apr 2020].

5 Garg S, Kim L, Whitaker M, et al. Hospitalization Rates and Characteristics of Patients Hospitalized with Laboratory-Confirmed Coronavirus Disease 2019 - COVID-NET, 14 States, March 1-30, 2020. MMWR Morb Mortal Wkly Rep 2020;69:458-64.

6 Dorn Avan, Cooney RE, Sabin ML. COVID-19 exacerbating inequalities in the US. Lancet 2020;395:1243-4.

7 Raifman MA, Raifman JR. Disparities in the population at risk of severe illness from COVID-19 by Race/Ethnicity and income. Am J Prev Med 2020;59:137-9.

8 Wu Z, McGoogan JM. Characteristics of and important lessons from the coronavirus disease 2019 (COVID-19) outbreak in China: summary of a report of 72314 cases from the Chinese center for disease control and prevention. JAMA 2020

9 CDC COVID-19 Response Team. Severe Outcomes Among Patients with Coronavirus Disease 2019 (COVID-19) - United States, February 12-March 16, 2020. MMWR Morb Mortal Wkly Rep 2020;69:343-346.

$10 \mathrm{Bi} \mathrm{Q}, \mathrm{Wu}$ Y, Mei S, et al. Epidemiology and transmission of COVID-19 in 391 cases and 1286 of their close contacts in Shenzhen, China: a retrospective cohort study. Lancet Infect Dis 2020;20:911-9.

11 Kissler SM, Tedijanto C, Goldstein E, et al. Projecting the transmission dynamics of SARS-CoV-2 through the postpandemic period. Science 2020;368:860-8.

12 Ferguson NM, Laydon D, Nedjati-Gilani G, et al. Impact of nonpharmaceutical interventions (NPIs) to reduce COVID19 mortality and healthcare demand, 2020. Available: https://sciencebusiness. net/sites/default/files/inline-files/Imperial-College-COVID19-NPImodelling-16-03-2020.pdf

13 Ahmed F, Ahmed Na'eem, Pissarides C, et al. Why inequality could spread COVID-19. Lancet Public Health 2020;5:e240.

14 Khullar D, Chokshi DA. Health, Income, \& Poverty: Where We Are \& What Could Help. Health Affairs, 2018.

15 Valentino-DeVries J, Lu D, Dance GJX. Location data says it all: staying at home during coronavirus is a luxury, 2020. Available: https://www.nytimes.com/interactive/2020/04/03/us/coronavirusstay-home-rich-poor.html [Accessed 4 Apr 2020].

16 Baker MG. Nonrelocatable occupations at increased risk during pandemics: United States, 2018. Am J Public Health 2020;110:1126-32.

17 Chen JT, Krieger N. Revealing the unequal burden of COVID-19 by income, race/ethnicity, and household crowding: US County vs ZIP code analyses. Harv Cent Popul Dev Stud Work Pap Ser 2020;19.

18 Group Quarters Definitions - 2018 ACS 1-year and 2014-2018 ACS 5-year Data Releases: Technical Documentation - Survey ACS 2018 (5-Year Estimates). Available: https://www.socialexplorer.com/ data/ACS2018_5yr/documentation/845ea049-8279-49ef-a8ac1cdd1fb49a10 [Accessed 23 Mar 2020].

19 Akiyama MJ, Spaulding AC, Rich JD. Flattening the Curve for Incarcerated Populations - Covid-19 in Jails and Prisons. N Engl J Med 2020;382:2075-7. 
20 Hawks L, Woolhandler S, McCormick D. COVID-19 in prisons and jails in the United States. JAMA Intern Med 2020. doi:10.1001/ jamainternmed.2020.1856. [Epub ahead of print: 28 Apr 2020].

21 Barnett ML, Grabowski DC. Nursing homes are ground zero for COVID-19 pandemic. JAMA Health Forum 2020;1:e200369.

22 Gandhi M, Yokoe DS, Havlir DV, et al. Asymptomatic transmission, the Achilles' heel of current strategies to control Covid-19. N Engl J Med 2020;382:2158-60.

23 Abrams HR, Loomer L, Gandhi A, et al. Characteristics of U.S. nursing homes with COVID-19 cases. J Am Geriatr Soc 2020;68:1653-6.

24 Baggett TP, Keyes H, Sporn N, et al. Prevalence of SARS-CoV-2 infection in residents of a large homeless shelter in Boston. JAMA 2020;323:2191-2.

25 Tsai J, Wilson M. COVID-19: a potential public health problem for homeless populations. Lancet Public Health 2020;5:e186-7.

26 Murray CJL, Kulkarni SC, Michaud C, et al. Eight Americas: investigating mortality disparities across races, counties, and racecounties in the United States. PLoS Med 2006;3:e260.

27 Krieger N, Rehkopf DH, Chen JT, et al. The fall and rise of US inequities in premature mortality: 1960-2002. PLoS Med 2008;5:e46.

28 Krieger N, Chen JT, Coull BA, et al. Jim Crow and premature mortality among the US black and white population, 1960-2009. Epidemiology 2014;25:494-504.

29 Bailey Z, Barber S, Robinson W, et al. Racism in the time of COVID-19. The interdisciplinary association for population health science, 2020. Available: https://iaphs.org/racism-in-the-time-ofcovid-19/

30 Cunningham TJ, Croft JB, Liu Y, et al. Vital Signs: Racial Disparities in Age-Specific Mortality Among Blacks or African Americans - United States, 1999-2015. MMWR Morb Mortal Wkly Rep 2017;66:444-456.

31 Dyer O. Covid-19: black people and other minorities are hardest hit in US. BMJ 2020;369:m1483.

32 Berchick ER, Barnett JC, Upton RD. Health insurance coverage in the United States: 2018. Washington, DC: U.S. Census Bureau, 2019. https://www.census.gov/content/dam/Census/library/publications/ 2019/demo/p60-267.pdf

33 U.S. Bureau of Labor Statistics. Unemployment rate by sex, race and Hispanic ethnicity 2016. Available: https://www.dol.gov/agencies/wb/ data/latest-annual-data/employment-rates [Accessed 6 Apr 2020].

34 NAACP. Criminal justice fact sheet. Available: https://www.naacp.org/ criminal-justice-fact-sheet/ [Accessed 6 Apr 2020].

35 Yancy CW. COVID-19 and African Americans. JAMA 2020;323:1891-2.

36 Bassett M, Chen JT, Krieger N. The unequal toll of COVID-19 mortality by age in the United States: quantifying racial/ethnic disparities. Harv Cent Popul Dev Stud Work Pap Ser 2020;19.

37 Hooper MW, Nápoles AM, Pérez-Stable EJ. COVID-19 and racial/ ethnic disparities. JAMA 2020;323.
38 Hamer S, Smith CC, Senol G, et al. COVID-19: California Counties and Cities Enact Stricter COVID-19 Policies than California's Statewide Stay-at-Home Order, 2020. Available: https://www. natlawreview.com/article/covid-19-california-counties-and-citiesenact-stricter-covid-19-policies-california [Accessed 22 Jun 2020].

39 Dunlap S. Georgia cities aim to slow COVID-19 with more restrictions than state, 2020. Available: https://georgiarecorder.com/2020/03/ 25/georgia-cities-aim-to-slow-covid-19-with-more-restrictions-thanstate/ [Accessed 22 Jun 2020].

40 Area health resources files, 2019. Available: https://data.hrsa.gov/ topics/health-workforce/ahrf

41 American community survey, 2018 American community survey 5year estimates, 2019. Available: https://www.census.gov/programssurveys/acs/data.html

42 Centers for Disease Control and Prevention. Interactive atlas of heart disease and stroke. Available: https://nccd.cdc.gov/DHDSPAtlas/

43 National Center for Health Statistics. Vintage 2018 postcensal estimates of the resident population of the United States (April 1, 2010, July 1, 2010-July 1, 2018), by year, County, single-year of age $(0,1,2,85$ years and over), bridged race, Hispanic origin, and sex 2019. Available: https://www.cdc.gov/nchs/nvss/bridged_race.htm

44 County Health Rankings \& Roadmaps: A Robert Wood Johnson Foundation Program, 2020. Available: https://www. countyhealthrankings.org/

45 Glanz J, Carey B, Holder J, et al. Where America Didn't Stay Home Even as the Virus Spread, 2020. Available: https://www.nytimes. com/interactive/2020/04/02/us/coronavirus-social-distancing.html [Accessed 6 Apr 2020].

46 Resnick B. "Totally predictable": State reopenings have backfired, 2020. Available: https://www.vox.com/science-and-health/2020/ 6/12/21288009/new-covid-spikes-arizona-florida-carolinas-texas [Accessed 26 Jun 2020].

47 Bosman J, Smith M. Coronavirus cases spike across sun belt as economy Lurches into motion, 2020. Available: https://www.nytimes. com/2020/06/14/us/coronavirus-united-states.html [Accessed 26 Jun 2020].

48 Halpern NH, Tan KS. United States Resource Availability for COVID-19, 2020May. Available from. Available: https://www.sccm. org/getattachment/Blog/March-2020/United-States-ResourceAvailability-for-COVID-19/United-States-Resource-Availability-forCOVID-19.pdf

49 Figueroa JF, Frakt AB, Jha AK. Addressing social determinants of health: time for a Polysocial risk score. JAMA 2020. doi:10.1001/ jama.2020.2436. [Epub ahead of print: 03 Apr 2020].

50 Smith M, Yourish K, Almukhtar S, et al. Coronavirus in the U.S. latest map and case count. Available: https://www.nytimes.com/ interactive/2020/us/coronavirus-us-cases.html

51 Chowkwanyun M, Reed AL. Racial Health Disparities and Covid-19Caution and Context. N Engl J Med 2020;383:201-3. 